\title{
@๑®ఠ Medicina e Educação no Século XVIII: Rousseau inventor de Emílio
}

\author{
Thomaz Massadi Kawauche
}

Resumo: Este artigo pretende examinar, no âmbito da história da medicina, as condições que possibilitaram a Rousseau conceber o modelo de criança descrito no Emílio. O objetivo é mostrar que os esquemas de inteligibilidade da pedagogia de Rousseau podem ser compreendidos no quadro dos debates médicos do Iluminismo acerca dos cuidados com o corpo infantil.

Palavras-chave: Educação, Medicina, Iluminismo, Rousseau, Ciências Modernas.

\section{Medicine and Education in Eighteenth Century: Rousseau inventor of Émile}

Abstract: This article intends to examine, within the History of Medicine, the conditions that enabled Rousseau to conceive the child model described in Émile. The aim is to show that the intelligibility schemes of Rousseau's Pedagogy can be understood in the framework of Enlightenment's Medical debates about infant body caring.

Keywords: Education, Medicine, Enlightenment, Rousseau, Modern Sciences.

\section{Médecine et éducation au XVIII ${ }^{\mathrm{e}}$ siècle: Rousseau inventeur d'Émile}

Résumé: Cet article se propose d'examiner, dans l'histoire de la médecine, les conditions qui ont permis à Rousseau de concevoir le modèle de l'enfant décrit dans l'Emile. Le but est de montrer que les schémas d'intelligibilité de la pédagogie de Rousseau peuvent être compris dans le cadre des débats médicaux des Lumières sur les soins du corps de l'enfant.

Mots-clés: Éducation, Médecine, Lumières, Rousseau, Sciences modernes.

\footnotetext{
* Doutor em Filosofia pela Universidade de São Paulo (USP). Bolsista PNPD-CAPES na Universidade Federal de São Carlos (UFSCAR). E-mail: kawauche@gmail.com
} 


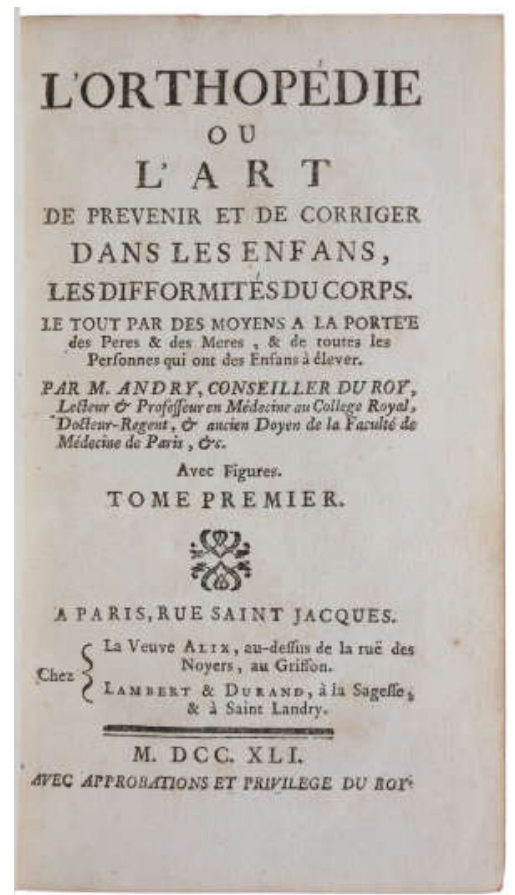

Polêmicas à parte quanto ao possível exagero em se rotular como "revolucionário" o pensamento pedagógico de Rousseau, o fato é que o autor do Emílio chegou ao século XX conhecido como o inventor da criança moderna. Essa imagem, como sabemos, tornou-se paradigmática após a publicação de L'Enfant et la vie familiale sous l'Ancien Régime (1960), de Philippe Ariès. ${ }^{1}$ De fato, a tese de Ariès sobre a produção social do corpo infantil e dos sentimentos implicados nesse processo - é confirmada em trechos do célebre tratado de educação do século XVIII, nos quais Rousseau afirma, em tom bastante crítico, a especificidade do período denominado infância. Destaco duas passagens célebres:

\footnotetext{
${ }^{1}$ Cf. trad. bras.: ARIÈS, 1981.
} 
Para não corrermos atrás de quimeras, não nos esqueçamos do que convém à nossa condição. A humanidade tem seu lugar na ordem das coisas, e a infância tem o seu na ordem da vida humana: é preciso considerar o homem no homem e a criança na criança. Determinar para cada qual o seu lugar e ali fixá-lo, ordenar as paixões humanas conforme a constituição do homem, é tudo o que podemos fazer pelo seu bem-estar. O resto depende de causas alheias que não estão em nosso poder. (ROUSSEAU, 1969, p. 303; 1999, p. 69)

A natureza quer que as crianças sejam crianças antes de serem homens. Se quisermos perverter essa ordem, produziremos frutos temporões, que não estarão maduros e nem terão sabor, e não tardarão em se corromper [...]. (ROUSSEAU, 1969, p. 319; 1999, p. 86)

Ora, sem a intenção de diminuir o mérito de Ariès, é preciso observar contudo que, cinquenta anos antes do livro que inaugura os estudos de história social da criança, esse ser chamado "enfant" já aparecia como objeto científico nas pesquisas do médico suíço Edouard Claparède (1873-1940) ${ }^{2}$. De acordo com o projeto de "educação funcional" de Claparède, Rousseau teria propiciado uma verdadeira revolução científica com o Emílio na medida em que propunha o conhecimento da infância considerando a criança enquanto criança, e não mais, à maneira de uma teleologia, como um adulto em potência. Devemos lembrar que, em L'Education fonctionnelle (1931), Rousseau é interpretado no viés do positivismo do início do século XX, segundo o qual Claparède busca conceber a educação enquanto ciência conjugando os quadros conceituais da biologia e da psicologia da época, notavelmente, a de William James (1842-1910); é nesse quadro histórico que podemos compreender o sentido do esforço desse pesquisador para investigar o comportamento da criança pautado por

\footnotetext{
${ }^{2}$ Claparède fundou em 1912 a École des Sciences de l'Éducation, também chamada Institut Jean-Jacques Rousseau. O Institut Rousseau tinha como proposta formar educadores com base em métodos de correntes pedagógicas hoje associadas à Escola Nova. Desde então, a École/Institut passou por diversas mudanças, até tornar-se, em 1975, a Faculdade de Psicologia e Ciências da Educação da Universidade de Genebra. Um dos discípulos mais célebres de Claparède foi Jean Piaget (1896-1980), que também trabalhou no Institut Rousseau.
} 
uma série de leis objetivas previamente enunciadas. No capítulo "J.-J. Rousseau e a concepção funcional da infância”, lemos a seguinte passagem que evidencia o essencial dessa "pedagogia experimental":

Em cada idade, pois, a criança é um ser perfeito - biologicamente falando é claro! "Cada idade, cada fase da vida tem sua perfeição conveniente, uma espécie de maturidade que lhe é própria. Muitas vezes temos ouvido falar de um homem feito; mas consideremos uma criança feita: será talvez mais novo para nós e não será menos agradável". E Rousseau, que tão bem soube ver "a criança na criança", nos descreveu ou, pelo menos, procurou descrever - e isso principalmente é que era novo e genial - uma criança "que viveu a vida de criança".

O resultado a que conduz essa concepção funcional da infância é que a criança não é simplesmente um homem inacabado, um homem imperfeito, ou reduzido, e sim um ser sui-generis. Daí não se deverá concluir, entretanto, que o princípio mesmo da atividade seja diferente num e noutro. $\mathrm{O}$ que difere são os mecanismos, a natureza dos interesses; mas a criança é semelhante ao homem no sentido de que, como nesse último, o que rege a atividade é a necessidade, é o interesse; do mesmo modo que, servindo-se embora um de uma brânquia o outro, de pulmão, o girino e a rã realizam a mesma função de respiração.

$\mathrm{O}$ homem e a criança possuem, pois, autonomia funcional. Essa identidade funcional, que estabelece uma relação de profunda semelhança entre o homem e a criança, a despeito de suas diferenças tão reais, não escapou a nosso autor: "Cada idade tem suas molas que a fazem mover-se; mas o homem é sempre o mesmo". (CLAPARĖDE, 1912, p. 412; 1958, p. 89)

A lei da autonomia funcional, que é uma das leis no modelo pedagógico descrito por Claparède, diz respeito a um dos princípioschave da antropologia de Rousseau: a liberdade autorregulada. Tudo se passa como se Emílio fosse transplantado para o quadro conceitual das ciências do final do século XIX. Em particular, as ideias pedagógicas de Claparède são bastante marcadas, como ele mesmo admite, pelo “instrumentalismo" de John Dewey (1859-1952), que é um dos autores que inspiram a teoria de L'Éducation fonctionnelle (cf. CLAPARÈDE, 1958, p. 20-21). Trata-se, evidentemente, de um contexto filosófico 
bem datado, e, por isso mesmo, a interpretação nele elaborada não poderia gozar de muito reconhecimento fora dos círculos pragmatistas. Porém, não é nenhum absurdo pensar que, do ponto de vista da história da pedagogia, o valor de tal leitura é patente: na condição de leitor do Emílio, o médico suíço demonstrou a fecundidade da doutrina da educação de Rousseau ao conseguir extrair dela uma teoria científica que, por um lado, correspondia às expectativas de uma comunidade de pesquisadores do século XX, e que, por outro, concedia à criança uma dignidade epistemológica comparável àquilo que Kant fez com o sujeito em relação aos objetos do conhecimento. Não é à toa que, referindo-se à especificidade que Rousseau reconhece na constituição infantil, Claparède, na respeitadíssima Revue de Metaphysique et de Morale, chama o autor do Emílio de "o Copérnico da pedagogia" por ter inventado "a arte da educação baseada numa concepção científica da criança" (ibid., p. 93). Do ponto de vista de sua pedagogia experimental, Claparède vê em Rousseau "o verdadeiro iniciador da ciência da infância”, cujo mérito foi “descobrir a criança” (CLAPARÈDE, 1916, p. 42, grifo do autor).

Nossas indagações podem, então, ser resumidas na seguinte pergunta: qual o sentido histórico em se afirmar que a pedagogia de Rousseau é revolucionária? Ora, mesmo referindo-se à ciência, Claparède não se preocupa em explorar a hipótese de que a novidade teórica trazida com a publicação do Emílio teria origem nos discursos médicos do século XVIII sobre a criança. Ariès, por sua vez, quase não fala de Rousseau, embora mencione algumas obras de medicina e reconheça a influência delas sobre a nova concepção do corpo infantil a partir do século XVII. Daí a proposta deste artigo: buscar compreender, no âmbito da história da medicina, o sentido dos epítetos que descrevem Rousseau como um escritor que revoluciona a pedagogia. Para tanto, procuro neste artigo examinar a noção comum de criança no Antigo Regime situando-a no quadro histórico e cultural de sua emergência, não apenas do ponto de vista das práticas e dos discursos 
que dizem respeito aos saberes médicos da época, mas também levando em conta os princípios filosóficos que sustentam o Emílio. O objetivo deste artigo é mostrar que, embora as teorias de Ariès e de Claparède se inscrevam em quadros conceituais diferentes, ainda assim trata-se de considerar, em ambos os casos, o corpo da criança como objeto científico, tanto no âmbito dos fatos quanto no dos modelos abstratos. A exposição que segue consiste em apontar, nos esquemas de inteligibilidade da pedagogia do Emílio, o registro médico em que se inscrevem as fontes de legitimidade dos discursos acerca da criança, quer para uma psicologia funcionalista como a de Claparède, quer para um estudo dos sentimentos em quadros históricos de longa duração, como o de Ariès.

$$
* * *
$$

A fim de compreendermos a transposição operada por Rousseau entre os saberes da medicina para os da pedagogia, convém que nossa primeira questão seja: qual o lugar da filosofia natural newtoniana em meio aos debates sobre medicina? Uma breve incursão na história das ciências modernas nos esclarecerá acerca desse ponto.

$\mathrm{O}$ autor do Emílio viveu na época em que o nome de Isaac Newton emblematizava os métodos de busca da verdade nas ciências. Todavia, essa recepção favorável de Newton, em particular na França, tinha um revés: a extensão nem sempre legítima dos domínios da filosofia natural. Não eram apenas astrônomos e químicos que se interessavam pela visão newtoniana da experiência, mas, de modo geral, todos que tentavam teorizar sobre os fenômenos empiricamente verificáveis. Para além das chamadas ciências da natureza, buscava-se investigar também o espírito humano de acordo com o método experimental na perspectiva da física newtoniana, donde se entende a grande adesão de filósofos ao - ou a algum tipo de - newtonianismo. Hume, por exemplo, atesta isso no subtítulo de seu Tratado sobre a natureza humana. Como explica o 
historiador Peter Gay (1977, p. 126), o endeusamento de Newton na França pela divulgação feita por Maupertuis e Voltaire não era sem razão: o autor dos Philosophiae naturalis principia mathematica (1687) havia estabelecido, melhor do que Descartes, um "estilo científico de pensamento", que, sem recorrer a hipóteses descoladas das observações físicas, oferecia uma sistemática de conciliação entre os dados da natureza e os modelos da geometria. A tentação era irresistível, de tal modo que aplicar o modelo newtoniano em outras áreas do conhecimento, como a moral e a política, acabou se tornando um lugar comum entre os philosophes.

No campo da medicina, a corrente que prevaleceu a partir do século XVII foi a de um "método histórico de classificação dos fenômenos" e, entre seus adeptos, defendia-se como princípio o "retorno a Hipócrates". 3 Grosso modo, podemos localizar o hipocratismo das Luzes no amplo quadro do empirismo, cuja marca distintiva era a investigação fundamentada na observação e na descrição de fenômenos particulares empiricamente verificáveis, e não em especulações teleológicas baseadas em hipóteses metafísicas que diziam respeito a explicações supostamente universais. Muito embora as conclusões elaboradas nos moldes do paradigma de Newton fossem sempre particulares e provisórias, ainda assim acabavam se mostrando preferíveis àquelas fundamentadas no método geométrico de Descartes, que cada vez mais se revelava inadequado para o estudo de fenômenos vitais, como o da geração dos seres vivos. Numa palavra, método experimental e medicina hipocrática eram praticamente sinônimos; o que não espanta se nos lembrarmos que a própria palavra "empirismo" surge em meio aos debates sobre a "medicina experimental" no século XVIII (cf. SALOMON-BAYET, 1978, p. 197-198).

\footnotetext{
${ }^{3} \mathrm{O}$ fundador dessa corrente é o médico inglês Thomas Sydenham (1624-1689), cujos escritos servirão de fundo doutrinal comum para os médicos do início do século XVIII, dentre os quais destaca-se o holandês Hermann Boerhaave (1668-1738). Cf. DUCHESNEAU, 1982, p. 26-28 e 477-478; GRMEK, 1997, p. 96-101 e 167-170; KING, 1978, p. 239-241.
} 
O problema se configurava, portanto, em termos de adequações buscadas no interior de um paradigma científico bem estabelecido. Nos casos de aplicação da teoria de Newton a problemas que não os da mecânica celeste, a transposição do modelo - ou do espírito do modelo - não era imediata. A medicina aparece aí como uma mediadora de registros discursivos que conquistavam reconhecimento sob a bandeira do método experimental. Pensadores como o naturalista Buffon, o médico La Mettrie e o filósofo Diderot quebravam a cabeça para descrever com rigor científico fatos observáveis como o coração da rã que continuava a bater após ser arrancado do corpo, ou o pólipo que, após ser cortado em pedaços, se regenerava em indivíduos inteiros a partir das partes separadas (cf. ROGER, 1997, p. 316 e 396). E as explicações eram transpostas para outros domínios de saberes - fala-se, por exemplo, dos órgãos sociais, do corpo político, etc. O poder de persuasão dos modelos da medicina, e em particular da fisiologia ${ }^{4}$, estava precisamente na possibilidade de demonstrar com dados empiricamente verificáveis a lógica dos organismos vivos; e esse modelo - pensava-se - poderia ser generalizado por analogias com a ajuda daquilo que François Duchesneau denominou "figuração 'newtoniana' dos princípios explicativos". ${ }^{5}$ Os teóricos da fisiologia, sobretudo em sua vertente iatromecanicista, se coadunavam com o newtonianismo no uso compartilhado de analogias descritivas. Não sem razão, Peter Gay (1977, p. 13) refere-se ao saber médico como modelo e prova dos raciocínios científicos no contexto das ciências experimentais: "Era em medicina que os philosophes testavam sua

\footnotetext{
${ }^{4}$ A bibliografia sobre o surgimento da fisiologia como ciência é vasta, cruzando-se com a dos autores que tratam do conceito de "economia animal". Por isso, cito apenas a referência que pode ser considerada a precursora de todas as demais: o artigo "La constitution de la physiologie comme science", de G. Canguilhem (1975).

5 "A heurística da fisiologia das Luzes vai se constituir sobre sistemas de analogias explicativas cujo papel não poderia ser subestimado, embora permaneçam aquém da modelização matemática. De maneira evidente, em numerosos casos esses modelos vão se estruturar assimilando uma figuração 'newtoniana' dos princípios explicativos." (DUCHESNEAU, 1982, p. xviii).
} 
filosofia pela experiência. A medicina era a uma só vez o modelo da nova filosofia e a prova de sua eficácia."

O diagnóstico de Peter Gay pode parecer generalista demais, mas não é: especialistas em história das ciências modernas, como François Duchesneau, Claire Crignon e Claire Salomon-Bayet, estudaram seriamente a relação entre o empirismo e a medicina. ${ }^{6} \mathrm{O}$ que estava em questão nessa época era o método de produção do conhecimento: em vez do método geométrico de Descartes, que mostrava-se incapaz de explicar o fenômeno da vida, havia uma ampla preferência pelo método experimental à maneira de Newton, ou seja, a observação dos fenômenos físicos passíveis de descrição por teorias particulares e provisórias evitando-se recorrer a especulações de tipo finalista. É nessa ambiência newtoniana, por assim dizer, que devemos contextualizar as afirmações de cunho empirista feitas por Rousseau no Emílio, como por exemplo: "O que me torna mais positivo e, segundo creio, mais desculpável por sê-lo é que, em vez de me entregar ao espírito de sistema, concedo o mínimo possível ao raciocínio e só confio na observação. Não me baseio no que imaginei, mas no que vi." (ROUSSEAU, 1969, p. 550; 1999, p. 338).

A perspectiva da história das mentalidades, apesar das críticas que já sofreu ${ }^{7}$, parece-me ainda hoje esclarecedora para termos uma noção da importância da medicina no pensamento pedagógico de Rousseau. $\mathrm{O}$ quadro histórico da criança no século XVIII mostra que os discursos de

\footnotetext{
${ }^{6}$ Sobre as fontes médicas da teoria do conhecimento de Locke, ver DUCHESNEAU, 1973. Sobre a origem médica do "empirismo" na história das ciências, ver SALOMON-BAYET, 1978, p. 197-198. Sobre o finalismo da medicina de Galeno no século XVII e o uso do nome de Hipócrates como emblema do método experimental, ver o artigo "The Debate about methodus medendi during the Second Half of the Seventeenth Century in England" em CRIGNON, 2013.

${ }^{7}$ Um interessante balanço crítico da tradição da história das mentalidades é apresentado em: HULAK, 2007-2008.
} 
medicina podem nos ajudar a apreciar aspectos menos explorados na interpretação do Emílio. Basta abrirmos um tratado como Médecine de l'esprit (1753, t. I, p. 257 e segs.), de Le Camus, para percebermos que a educação moral das crianças levava em conta, em primeiro plano, fatores que um médico observaria: disposição dos órgãos, climas, regimes, sangue, fibras, suco nervoso, etc. Isso porque, na perspectiva da físiologia, a educação das crianças era comparável ao cultivo de plantas - metáfora de Le Camus (ibid., p. 258) que Rousseau reproduz na abertura do Emílio -, e, de acordo com essa opinião, uma das responsabilidades do educador era a de preservar a vida do educando; ou seja, educar crianças no século XVIII tinha o sentido de fazê-las crescer com boa constituição física, como sugere a palavra "élevage". ${ }^{8}$

Para termos uma melhor noção do contexto, podemos recorrer a Elisabeth Badinter (1980, p. 139), que nos fornece algumas estatísticas em seu livro sobre a invenção do amor materno: nos séculos XVII e XVIII, a taxa de mortalidade dos bebês com menos de um ano era

\footnotetext{
${ }^{8}$ Rousseau se refere à educação como uma arte, e para designar as obras dessa arte, utiliza os verbos façonner e élever. Diz-se que a criança é façonné, assim como se diz que a terra do agricultor foi preparada ou lavrada. O sentido é de um trabalho humano realizado sobre um dado da natureza, e, em língua portuguesa, pode-se utilizar as palavras elaborar, moldar, modelar ou conformar. Quanto a élever, trata-se de um verbo com sentido de fazer crescer, aplicável não somente às artes agrícolas, mas também à criação de animais. A necessidade de se usar élever ou façonner para indicar a ação do educador se explica pelo léxico da época: embora fossem conhecidas as formas latinas educere (conduzir, comandar, guiar) e educare (criar, formar, instruir), e embora sejam registradas ocorrências de éduquer na literatura francesa do século XIV, o verbo éduquer só ganhou lugar de uso corrente na língua francesa no século XIX. Os dicionários da época nos mostram que a aproximação entre o substantivo éducation e o verbo façonner era usual. O Dictionnaire de l'Académie française, por exemplo, traz em sua quarta edição, de 1762, a seguinte definição para "Façonner": "Em termos de Agricultura, diz-se do labor que se realiza na vinha, nas terras. Preparar uma vinha, uma terra, um campo". Quanto a élever, na edição de 1762 do mesmo Dictionnaire de l'Académie, a definição que fixa mais de perto o sentido de élever no texto de Rousseau é a que define a palavra nutrição: "Nutrir uma criança até que ela chegue à idade da razão". Havia, porém, outras definições, uma delas aplicável a plantas e animais, e que também serve no texto do Emílio: "Diz-se também dos outros animais e até mesmo das árvores e das plantas. Os pavões são difíceis de criar [élever]."
} 
sempre superior a $25 \% .{ }^{9}$ Nesse contexto não deixa de ser notável a expressão "éducation médicinale", criada pelo médico Pierre Brouzet (1754, t I, p. ii), que parece sintomática de uma preocupação: que a sobrevivência das crianças era de fato um problema social (lembremos dos fisiocratas, como Mirabeau, que viam no aumento da população um sinal de progresso econômico) tão sério a ponto de justificar a publicação de tratados de medicina sobre o assunto. Ou seja, falar de criança no século XVIII é falar, não de um receptáculo de conhecimentos ou de um autômato civilizado, como um tipo de honnête-machine (em referência a manuais de civilidade, como os de Erasmo, que visavam o ideal do honnête-homme), mas de um ser vivo, como um "arbusto nascente" ou uma "jovem planta" (ROUSSEAU, 1969, p. 246; ed. bras., p. 8), cuja permanência no mundo dos viventes é um desafio. Em suma, a "élévage", que traduzimos por "educação" ou "formação", deve ser entendida como obra de arte em sentido amplo e com efeitos sociais seríssimos, o que motiva Rousseau e outros autores do século XVIII a pensarem na conexão necessária entre certos ramos da medicina - como por exemplo, o da arte da higiene - e os saberes pedagógicos. ${ }^{10}$

Porém, numa visada mais larga do quadro histórico, não se trata apenas de um problema de higiene, ou seja, de medicina útil. Pois, o que notamos em obras como, Essai sur l'éducation médicinale des enfants et sur leurs maladies (1754), de Brouzet, ou Traité des maladies des enfants (1759), de Boerhaave e Van Swieten, ou L'Education corporelle des enfans en bas-âge (1760), de Desessartz, ou ainda L'Onanisme (1760), de Tissot, é que, consideradas em conjunto,

\footnotetext{
${ }^{9}$ Esses dados podem ser confirmados em BLAYO, 1975. Para efeito de comparação, dados referentes a 2015 divulgados pelo IBGE indicam que a taxa de mortalidade no Brasil para crianças com menos de um ano é de 13.8 por mil nascidos vivos, ou seja, $1.38 \%$.

${ }^{10}$ Diga-se de passagem que a higiene é a única parte da medicina que Rousseau não critica no Emílio: "A única parte útil da medicina é a higiene, e mesmo assim a higiene é menos uma ciência do que uma virtude. A temperança e o trabalho aguça seu apetite e a temperança impede que abuse dela.” (ROUSSEAU, 1969, p. 271; 1999, p. 35). Sobre o problema da dissidência higiênica de Rousseau, cf. LA MENTHÉOUR, 2011.
} 
elas formam um corpus que, no âmbito das controvérsias científicas, sugere uma mudança de mentalidade. ${ }^{11} \mathrm{O}$ verbete "Crianças (Doenças das)" da Encyclopédie, é representativo desse movimento de pesquisa médica aplicada à "proteção das crianças contra tudo o que represente ameaça à sua vida". ${ }^{12}$ Com efeito, publicações desse tipo, que legitimam a representação da criança como um ser vivente com necessidades próprias relativas à sua constituição, podem ser vistas como sinais de uma mudança das representações e dos quadros conceituais nas ciências da saúde. Nesse processo de individualização do corpo infantil sob o olhar médico, ideologicamente amparado por uma noção tradicional da criança como "rebento de um tronco de linhagem familiar" ${ }^{13}$ que precisava ser preservada a todo custo, os modelos antropológicos dos filósofos e dos teóricos da educação poderiam ser vistos como extensão do sistema. Não sem razão, Alain Renaut (2003, p. 80) se refere a uma "primeira revolução médica concernente à infância" ao diagnosticar o contexto em que a representação do aluno imaginário chamado Emílio é gestada.

Por outro lado, não quero com essa interpretação afirmar que a moda editorial de tratados de medicina sobre o corpo infantil

\footnotetext{
${ }^{11}$ Em seu estudo das fontes do Emílio, Jimack menciona e comenta as referências médicas de Rousseau: Boerhaave, Brouzet, Desessartz, além dos tratados sobre saúde e alimentação de John Arbuthnot, Antonio Celestino Cocchi e Giovanni Bianchi (cf. JIMACK, 1960, p. 364-368).

12 "É, portanto, muito importante ao gênero humano, cuja conservação é confiada aos médicos, que se encarreguem, por assim dizer, da proteção das crianças contra tudo o que represente ameaça à sua vida; que se apliquem em estudar os males aos quais elas são particularmente sujeitas [...]." (Encyclopédie, tomo V, p. 657). O autor desse verbete é Arnulphe d'Aumont, médico francês.

13 "Entre o destino coletivo ao qual toda criatura estava intimamente ligada e o gozo individual dos prazeres da existência - a aspiração de "viver a própria vida", que consideramos legítima - havia uma contradição, cabendo a prioridade ao corpo cuja continuidade se devia garantir a qualquer preço: o corpo da linhagem. $\mathrm{O}$ indivíduo dispunha do próprio corpo somente na medida em que não contrariasse os interesses da família. [...] Nesse imaginário da vida e do corpo, a criança era considerada um rebento do tronco comunitário, uma parte do grande corpo coletivo que, pelo engaste das gerações, transcendia o tempo. Assim, pertencia à linhagem tanto quanto aos pais. Neste sentido, era uma criança "pública'.” (GELIS, 2009, p. 306).
} 
contribuía necessariamente para a formação do sentimento de ternura dos pais em relação aos filhos. Em alguns casos talvez sim, como em L'Education corporelle des enfans en bas-âge, onde Desessartz dá recomendações que, na prática, resultavam num maior tempo de contato físico entre mãe e bebê, como por exemplo, quando fala dos cuidados no primeiro dia do bebê relativos ao momento certo de cortar o cordão umbilical (cap. I, art. 2). Esse cuidado médico que acabava engendrando afetividade em relação às crianças também se verifica quando Desessartz toma posição na polêmica do aleitamento: "O leite é o melhor alimento que se pode dar à criança recémnascida." (cap. III, art. 1). ${ }^{14}$

Em contrapartida, havia autores que hoje nos parecem mais difíceis de serem entendidos. Cito agora um exemplo que, semelhantemente aos textos médicos que condenavam a masturbação Onanismo de Tissot (1760) é o exemplo mais famoso -, mostra o lado sinistro, por assim dizer, do processo de reconhecimento social do corpo infantil. Nicolas Andry de Bois-Regard é autor de Ortopedia, ou $A$ arte de prevenir e corrigir nas crianças as deformidades do corpo (1741). A palavra "ortopedia" foi inventada por ele.

Quanto ao título em questão, formei-o de duas palavras gregas, a saber, orthos que quer dizer reto, isento de deformidade, que é segundo a retidão, e paidion, que significa criança. Compus dessa duas palavras ortopedia para exprimir, em um único termo, o projeto que me proponho, que é ensinar diversos meios de prevenir e corrigir nas crianças as deformidades do corpo. (BOIS-REGARD, 1741, t. I, p. ii)

\footnotetext{
${ }^{14}$ Sobre o aleitamento materno, a perspectiva de Rousseau é a da medicina social da época. $\mathrm{O}$ autor do Emílio incentiva que as mães amamentem seus bebês com o intuito de reformar os costumes e repovoar o Estado (ROUSSEAU, 1969, p. 258; 1999, p. 21). Temos aí uma teoria do fenômeno do despovoamento, que encontraria uma de suas causas na moda - ou no costume - das mães que preferiam não amamentar seus filhos. Como explica Elisabeth Badinter (1980, p. 95-100), as mulheres da aristocracia buscavam seu lugar na sociedade e o aleitamento era visto como um entrave: elas recorriam a argumentos físicos (perda da saúde), argumentos estéticos (perda da beleza) e argumentos sociais (perda de visibilidade, pois para amamentar precisariam se recolher para os ambientes de intimidade). Um problema de opinião e "moeurs", diria Rousseau.
} 
Dentre as recomendações ortopédicas, estão, por exemplo, as regras para endireitar as pernas da criança com placas de ferro amarradas para impedir a flexão dos joelhos. Sobre a prática do enfaixamento (cueiros), Bois-Regard é minucioso a ponto de recomendar que as faixas não apertassem demasiadamente os ombros, pois isso produziria uma curvatura das clavículas que poderia deformar o peito da criança. É notável a ilustração (Figura 1) entre as páginas 282 e 283 do tomo I do livro Ortopedia que apresenta uma árvore amarrada num tutor (nome que, em agricultura, se dá à estaca cravada na terra para amparar e direcionar o caule das plantas). Essa imagem pedagógica deve ter chamado a atenção de Michel Foucault, pois ele a reproduz em Vigiar e punir, obra em que disserta sobre a função de "ortopedia social" associada às instituições prisionais.

Todavia, devemos compreender o movimento de publicação de obras médicas sobre os cuidados com os corpos das crianças, não como um processo isolado, mas como um conjunto de mudanças que ocorria concomitantemente com a incorporação cada vez maior das regras de civilidade. Nessa questão, os trabalhos de Norbert Elias (1939) e Philippe Ariès (1960) nos permitem contextualizar o Emílio na tradição pedagógica cuja principal marca eram os manuais pedagógicos que ensinavam regras de bom comportamento. A história dessas obras, que remontam a Erasmo de Rotterdam, passa por autores como La Salle, Montaigne, Fénelon e Locke. ${ }^{15}$ De modo geral, seus autores tinham em vista a formação do homem civil: o honnête-homme ou gentleman. $\mathrm{O}$ método educativo da pedagogia da civilidade consistia em incorporar, desde a mais tenra idade, certos hábitos que se coadunavam com as regras de etiqueta da sociedade das cortes europeias dos séculos XVI e XVII, de tal maneira que a criança assim educada pudesse se tornar um indivíduo apto para disputar posições de distinção na sociedade burguesa emergente. O manual de Erasmo, De civilitate morum

\footnotetext{
${ }^{15}$ Um estudo recente em história da educação com excelente pesquisa de fontes é o livro $A$ liturgia escolar na Idade Moderna, de Carlota Boto (2017).
} 
puerilium (1530), é, como ensina Elias, o exemplo emblemático dessa tradição.

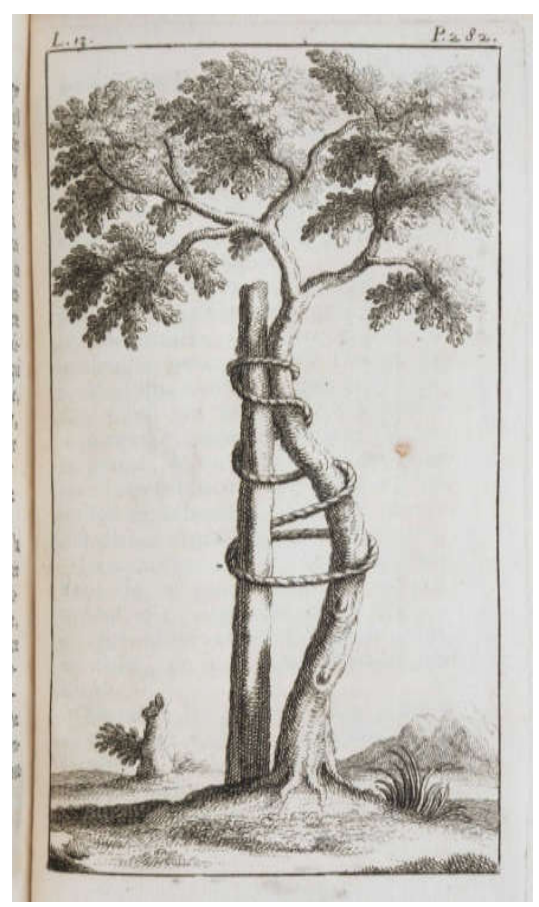

Figura 1: Página de rosto e ilustração de L'Orthopédie (1741).

Polêmicas à parte quanto à aceitação do método investigativo de Elias e Ariès - ao qual hoje é referido sob a rubrica de "história das mentalidades" -, um fato é certo: foi justamente esse viés do pensamento que deu origem a pesquisas seminais nas áreas de filosofia e pedagogia. Em particular, Ariès inaugurou o campo epistemológico da história social da criança, que serviu de matriz para investigações que examinaram as relações de poder implicadas nas regras ligadas, direta ou indiretamente, ao ocultamento da sexualidade da criança. Michel Foucault, por exemplo, no primeiro volume da História da 
sexualidade (1984), analisa a produção social do corpo infantil decorrente das proibições relacionadas ao onanismo, o que não deixa de ser um eco das pesquisas de Ariès (cf. 1981, p. 49-51) sobre a construção da ideia de inocência infantil na representação do corpo absolutamente assexuado de um anjo (Figura 2), como o "putto" das pinturas religiosas que se tornaram comuns a partir do final do século XVI. ${ }^{16}$

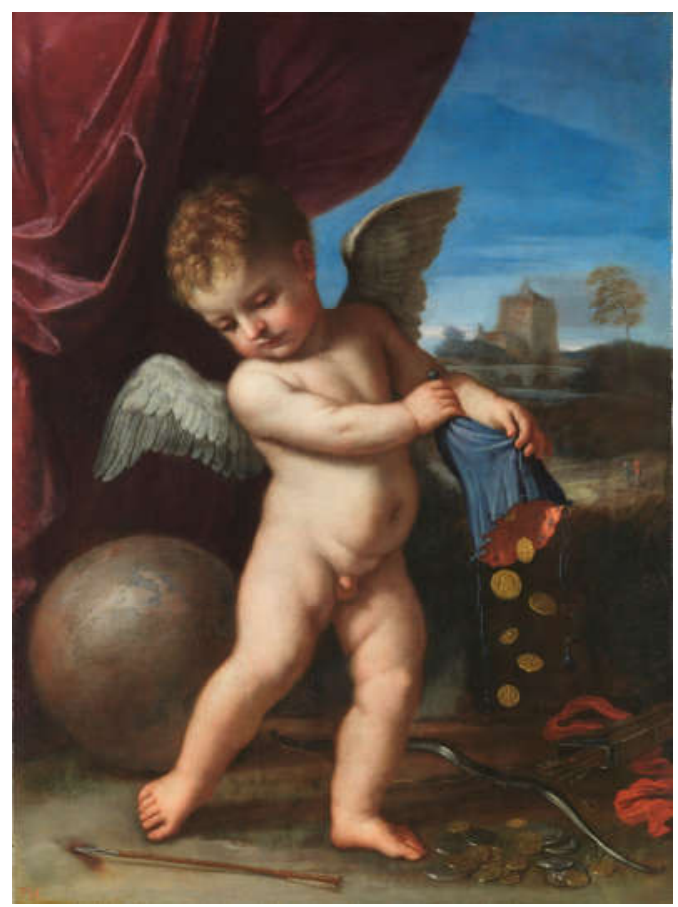

Figura 2: Giovanni "Il Guercino" Barbieri (1591-1666), "O amor desinteressado" (1654), 99 x $75 \mathrm{~cm}$, Museo del Prado, Madrid.

${ }^{16}$ É instrutivo notar que a palavra original do latim, puto, tinha o sentido de "limpar, purificar", e que a locução utilizada era "purum putum", podendo ser traduzida como "puro e sem mistura" (cf. ERNOUT \& MEILLET, 2001, p. 548). 
Ora, a despeito da veracidade dessa representação, não se pode negar que havia diferenças perceptivas na maneira como as crianças eram retratadas no século XVIII em comparação com os retratos da Idade Média. Veja-se, por exemplo, as telas "Madona e seu filho" (Figura 3), de Berlinghiero Berlinghieri (1175-1236), e o "Autorretrato com sua filha Julie" (Figura 4), de Elisabeth Louise Vigée Le Brun (1755-1842). Vigée Le Brun, conhecida como a retratista da rainha Maria Antonieta, era leitora e admiradora de Rousseau e, não sem razão, a tela em questão é apelidada de "ternura materna".

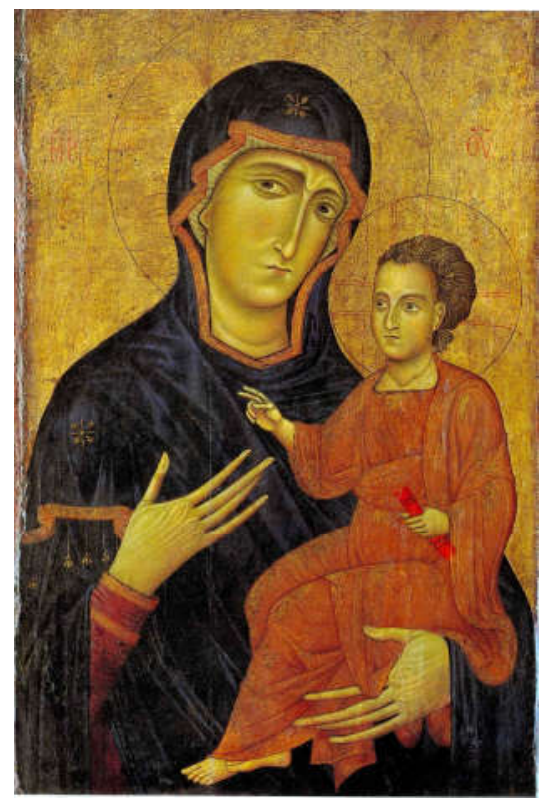

Figura 3: Berlinghiero Berlinghieri (1175-1236), "Madona e seu filho" (1230), 80 x $54 \mathrm{~cm}$, Metropolitan Museum of Art, Nova York.

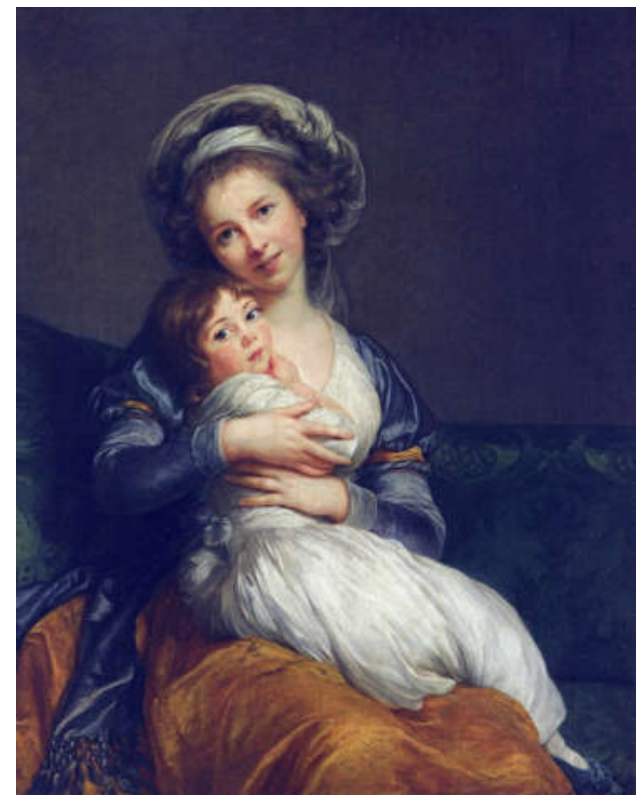

Figura 4: Elisabeth Louise Vigée Le Brun (1755-1842), "Autorretrato com sua filha Julie" (1786), 105 x 84 cm, Musée du Louvre, Paris. 
Contudo, é preciso ponderar acerca dos limites dessa diferença. Embora o olhar sobre a criança tenha efetivamente mudado, ainda assim a visão finalista do ser humano típica do pensamento medieval permanecia: fosse um adulto em miniatura (como afirmava Ariès) ou não ${ }^{17}$, a criança continuava a ser concebida como um adulto em potência, ou ainda, um ser imperfeito cujo telos seria, ao fim e ao cabo da vida, tornar-se um adulto. Mais do que isso, essa permanência do finalismo, que se verificava até o século XVII nos modelos fisiológicos inspirados em Galeno, servia para mascarar as relações de poder que perpassavam as relações entre pais e filhos. Como mostra Foucault (1999, p. 100-108), eram as relações de poder pautadas pelos "dispositivos de sexualidade" no seio da família burguesa moderna que imperceptivelmente condicionavam os costumes e, na medida em que eram legitimadas nos discursos de pais, pedagogos e médicos, acabavam estruturando toda a sociedade. Ou seja, não era por acaso que a criança, até o século XVIII, era definida negativamente do ponto de vista ontológico (infans, isto é, aquele que não fala; innocens, ou seja, aquele que não comete o mal com ciência moral de um adulto), em termos de uma falta de humanidade a ser remediada no processo de aperfeiçoamento conduzido pela educação, bem no espírito do methodus medendi da medicina finalista de Galeno.

A novidade introduzida por Rousseau foi dupla: por um lado, ele critica as interdições relacionadas à sexualidade do corpo da criança, e por outro, recusa-se a entender o despertar dos desejos sexuais na adolescência em termos de uma vida humana regida por causas finais. Ao dividir a vida de Emílio em dois nascimentos, um "para a espécie" e outro "para o sexo" (ROUSSEAU, 1969, p. 489; 1999, p. 271), o genebrino relativiza a função dos tabus na formação do ser humano e abre espaço para a investigação das determinações próprias de uma ordem independente daquela ligada à sexualidade dos adultos. Exponho

17 Para uma interpretação que contesta radicalmente Ariès, cf. SHAHAR, 1990. Ver também a coletânea FASS, 2013. 
a seguir, em linhas gerais, esses dois aspectos do novo olhar de Rousseau sobre a criança.

Antes da idade da razão (dos 15 aos 18 anos, cf. livro IV), a recomendação é que Emílio não seja submetido a discursos de recato, decoro, pudicícia, etc. $\mathrm{O}$ corpo da criança até a pré-adolescência deve se desenvolver, segundo Rousseau, sem o condicionamento das regras e proibições que refletem os costumes corrompidos, pois, em caso contrário, a própria faculdade de raciocínio, que não é um dado natural e sim obra da educação, será determinada pelos "dispositivos de sexualidade", para falarmos como Foucault. Fiel ao princípio de equilibrar os progressos da imaginação e da força física, Rousseau propõe a abolição das lições que encobrem a sexualidade com as regras de civilidade, uma vez que tais regras só serviriam para atiçar a curiosidade infantil e, por conseguinte, despertar precocemente os desejos sexuais sem a contrapartida da razão que poderia contê-los:

Embora o pudor seja natural à espécie humana, as crianças não o têm naturalmente. O pudor só nasce com o conhecimento do mal; e como as crianças, que não têm nem devem ter esse conhecimento, teriam o sentimento que é o seu efeito? Dar-lhes aulas de pudor e de decência equivale a ensinar-lhes que existem coisas vergonhosas e indecentes, e dar-lhes um secreto desejo de conhecer essas coisas. [...] Todo aquele que cora já é culpado; a verdadeira inocência de nada tem vergonha. (ROUSSEAU, 1969, p. $497-498 ; 1999$, p. 280)

Ou seja, Rousseau rompe com o ideal de "inocência" de sua época e busca a autonomia da ordem da infância na medida em que nega a autoridade das lições verbais antes que, segundo a "marcha da natureza", a própria razão tenha condições materiais de impor-se, ela mesma, como autoridade. Daí o sentido inovador de afirmações pedagógicas que incentivavam a educação física das crianças $^{18}$, como:

\footnotetext{
${ }^{18}$ Montaigne e Locke são autores importantes para as considerações que Rousseau faz sobre a educação física (cf. KAWAUCHE, 2017).
} 
"É preciso que o corpo tenha vigor para obedecer à alma" (ROUSSEAU, 1969, p. 269; 1999, p. 32), ou "Não deis a vosso aluno nenhum tipo de lição verbal. Ele deve receber lições somente da experiência; [...] ele não sabe o que é ser culpado [...]" (id., 1969, p. 321; 1999, p. 89), etc.

Além disso, Rousseau reinterpreta a diferença essencial entre crianças e adultos em termos mais radicais do que faziam os pedagogos de seu tempo: ele vê nessa diferença a justificativa para que a criança receba cuidados próprios para a sua condição atual, de tal modo que um indivíduo, em qualquer fase de seu crescimento, seja capaz de alcançar a felicidade, não na perspectiva finalista da vida humana em geral, mas a cada instante de sua existência historicamente situada. Não nos enganemos com fórmulas como: "É preciso ser feliz, caro Emílio, tal é o fim de todo ser sensível; é o primeiro desejo que a natureza imprimiu em nós, e o único que nunca nos abandona" (id., 1969, p. 814; 1999, p. 623). Porque, logo em seguida, nosso autor se indaga: "Mas onde está a felicidade? Quem o sabe?". Nenhum espanto aí, uma vez que a felicidade, assim como a constituição momentânea da criança, é, segundo Rousseau, uma questão de história, e não de metafísica. Por isso, em vez da eudaimonia como finalidade absoluta da ética que remonta a Aristóteles, Rousseau propõe para todas as etapas da vida do indivíduo a bonheur (os etimólogos falam em boa hora, no sentido de uma ocasião oportuna para o bem ou para o mal, como um kairós oferecido pela fortuna), ou seja, felicidades - no plural, pois não dizem respeito à causa final do homem - instantâneas e sucessivas:

$\mathrm{Na}$ incerteza da vida humana, evitemos sobretudo a falsa prudência de imolar o presente pelo futuro; isso não raro equivale a imolar o que é pelo que não será. Tornemos o homem feliz em todas as idades, para que, depois de tantos trabalhos, ele não venha a morrer antes de ter sido feliz. (ROUSSEAU, 1969, p. $781 ; 1999$, p. 587) 
Emílio personifica a recusa da noção de criança como adulto-emdevir. O princípio basilar dessa doutrina é a distinção entre ordem da infância e ordem da vida humana. Vale a pena rememorarmos a passagem (citada no início deste artigo) que costuma ser usada para se afirmar que Rousseau inventou a criança moderna: "A natureza quer que as crianças sejam crianças antes de serem homens. Se quisermos perverter essa ordem, produziremos frutos temporões, que não estarão maduros e nem terão sabor, e não tardarão em se corromper [...]" (id., 1969, p. 319; 1999, p. 86). Ana Beatriz Cerizara, com grande perspicácia, lembra que Rousseau utiliza, no final do livro II, a paradoxal expressão "maturidade da infância" (id., 1969, p. 423; 1999, p. 198) para comunicar essa nova maneira de ver a criança. É nesse sentido que Cerizara (1990, p. 82) afirma que nosso autor pode ser visto como um "pensador revolucionário".

Pode-se dizer que, no Emílio, não se trata de educar um homem inacabado, como se a plenitude do ser só pudesse ser atingida na idade adulta. Rousseau não tem em vista um fim, um estado ideal que deve ser atingido pelo progresso determinado ao longo do caminho da boa educação. Tudo isso é essencialista demais para o genebrino, que prefere separar ordem natural e ordem civil, a fim de analisar a realidade social estritamente como artifício produzido pelas mãos humanas. Em vez de idealizar " $a$ " boa educação, ele pensa em regras práticas tiradas da própria experiência histórica, que dizem respeito a um conhecimento útil para a vida. Numa palavra, Rousseau considera a criança como um ser perfeito em si mesmo a cada instante de sua existência, mesmo sem saber qual seu telos, sua destinação absoluta, seu fim último. "Cada tipo de instrução tem seu tempo próprio, que é preciso conhecer, e seus perigos, que é preciso evitar" (ROUSSEAU, 1969 , p. $655 ; 1999$, p. 451). Ao recusar a representação da criança como adulto em potência e propor uma educação baseada em um saber técnico como o das artes mecânicas (lembremos que Emílio será marceneiro, e não filósofo, cf. livro III), Rousseau se coloca num 
quadro epistemológico em que a concepção finalista da educação não tem sentido. Emílio não é educado segundo leis que visam o fim universal a que todo homem deve chegar (que diriam respeito às artes liberais); em vez disso, adequa-se a regras práticas que variam de acordo com as circunstâncias, tendo em vista um fim particular que diz respeito à particular constituição de cada indivíduo educado.

Rousseau, assim como todos os seguidores do método experimental à maneira de Newton, limita suas investigações aos fenômenos observáveis. Veja-se nessa recusa das causas finais para falar da criança - e do homem - uma inspiração mecanicista da ciência da educação. É nesse sentido, e tão-somente nesse sentido, que podemos atribuir a Rousseau a invenção da infância: ele busca, mais do que todos os pensadores até então, as necessidades adequadas a cada momento da vida desse personagem fictício que é Emílio, do bebê recém-nascido até o jovem em idade própria ao casamento; e, o que é mais notável, Rousseau faz isso no interior do quadro conceitual das ciências da natureza em debate naquele momento da história.

Evidentemente, Rousseau não foi o primeiro nem foi o único pensador a considerar as necessidades próprias da criança a cada etapa de seu desenvolvimento. Num certo sentido, até Platão na República pode ser visto como um teórico das etapas da vida humana. Mas, no contexto das ciências modernas, o modelo antropológico adotado por Rousseau aparece de modo notável como o emblema de uma maneira de pensar de toda uma época: Emílio é um modelo abstrato construído nos moldes do método experimental da física pós-Newton. Assim como na história das ideias políticas, também na história da pedagogia Rousseau opera um paradoxo: leva o conhecimento do homem para além dos limites considerados por seus contemporâneos na medida em que o enraíza nos quadros conceituais das ciências da época, como a história natural ou a química. O radicalismo no modelo antropológico da criança no Emílio é comparável ao radicalismo da hipótese do homem em estado de natureza no Discurso sobre a origem da 
desigualdade. Porém, convém observar que, acima de tudo, trata-se de um radicalismo premeditado, que diz respeito a um método científico.

Empirismo e medicina se confundem. Como mostra SalomonBayet (1978, p. 197-198), o termo "empirismo" tem origem nos debates sobre a fisiologia entendida como economia animal a partir do Essai physique sur l'économie animale, publicado por Quesnay em 1736. E nesses debates, estavam em questão não apenas a noção de conhecimento determinado pela observação dos fenômenos físicos, mas também o retorno a Hipócrates. Pois era Hipócrates, com seu método de observar e descrever a physis sem buscar interpretá-la, combinado a uma doutrina dos humores capaz de explicar o funcionamento interno do corpo-máquina, quem fornecia um dos paradigmas mais respeitáveis do pensamento científico moderno. Isso, todavia, não significa que o paradigma da medicina hipocrática estivesse isento de dificuldades. Pelo contrário, os modelos da filosofia experimental estavam todos em processo de elaboração, e até mesmo esquemas de inteligibilidade que contavam com ampla aceitação, como os do iatromecanicista Hermann Boerhaave (1668-1738) ${ }^{19}$, tinham suas complicações indemonstráveis, como a correspondência imediata entre o modelo humoral e os modelos hidráulicos; complicações estas que tornavam-se ainda mais obscuras com o uso corrente de categorias operatórias do galenismo, como "humores sutis" e "espíritos animais". De todo modo, esse era o espírito da "medicina experimental" que Thomas Kuhn chamaria de "ciência normal" passível de mudanças estruturais.

Este artigo não poderia terminar sem algumas considerações sobre a relação entre Boerhaave e Rousseau, pois sabemos que o Cidadão de

\footnotetext{
${ }^{19}$ Boerhaave foi professor na Universidade de Leiden e exerceu enorme influência sobre os filósofos europeus nas áreas de fisiologia, química e botânica. É conhecido como autor de um dos grandes compêndios de medicina da época: as Institutiones rei medicae (1708). Como princípio metodológico, Boerhaave defendia, como bom newtoniano que era, o retorno a Hipócrates (cf. Oratio de commendando studio Hippocratico, de 1701). Haller, um dos mais célebres discípulos do holandês, chamou seu mestre de "communis Europae Praeceptor", o preceptor comum da Europa. Cf. LINDEBOOM, 1968, p. 3 e 355.
} 
Genebra era muito interessado nas ciências de seu tempo, tendo inclusive utilizado o manual de química de Boerhaave quando, por volta de 1747, redigiu suas Instituições químicas (cf. BENSAUDEVINCENT \& BERNARDI, 2003). Além disso, embora o nome de Boerhaave só apareça uma vez no Emílio,${ }^{20}$ diversas lições dos escritos boerhaavianos - incluídas aí as lições dos comentadores das obras, como Van Swieten - encontram-se nas prescrições sobre a saúde da criança. Com efeito, a passagem, no livro I, sobre o cuidado com as febres durante o processo de dentição é praticamente uma paráfrase dos comentários de Van Swieten no Traité des maladies des enfants. ${ }^{21}$ Ainda no Emílio, não nos passa despercebida a menção ao sensorium commune na descrição do bebê (ROUSSEAU, 1969, p. 280; 1999, p. 44), bem como o modelo da economia animal para a descrição dos progressos do corpo infantil nos livros II e III, ${ }^{22}$ que me parecem referências bastante claras ao iatromecanicismo de Boerhaave ou, pelo menos, ao debate sobre fisiologia na primeira metade do século XVIII (devemos lembrar que o "sensorium commune" aparece na passagem

\footnotetext{
${ }^{20}$ A menção explícita encontra-se em ROUSSEAU, 1969, p. 287; 1999, p. 52.

${ }^{21}$ Comparar ROUSSEAU, 1969, p. 259 com BOERHAAVE \& VAN SWIETEN, 1759, $\S 1374$, p. 341-342.

${ }^{22}$ Nota-se, por exemplo, as expressões no Emílio que evocam a imagem da "máquina", a começar pela descrição do bebê: "Os movimentos, os gritos da criança que acaba de nascer são efeitos puramente mecânicos, carentes de conhecimento e de vontade" (ROUSSEAU, 1969 , p. 280; 1999, p. 44); ou ainda, quando menciona "as operações da máquina e as do juízo" em referência ao hábito do corpo e do espírito (id., 1969, p. 393; 1999, p. 165); Rousseau fala das "fibras da criança" e compara o corpo infantil a uma "máquina semelhante" (id., 1969, p. 402; 1999, p. 175). Os exemplos também são claros quando Rousseau utiliza a palavra "constitution": "Todos os seus movimentos são necessidades de sua constituição, que procura fortalecer-se (id., 1969, p. 312; 1999, p. 78-79); “Assim, longe de a verdadeira razão do homem formar-se independentemente do corpo, é a boa constituição do corpo que torna fáceis e seguras as operações do espírito." (id., 1969, p. 370; 1999, p. 141). Todavia, a questão é complexa, pois sabemos que Rousseau rejeita explicitamente a comparação com o modelo mecânico quando considera a formação de Emílio do ponto de vista moral, sobretudo no livro IV, quando entra em cena o "princípio ativo" como origem do movimento e, por conseguinte, como fonte da ação moral, que parece inspirar-se no "princípio vital" de Bordeu e, de modo geral, nas doutrinas vitalistas da Escola de Montpellier. Sobre o vitalismo na França dos séculos XVIII e XIX, cf. REY, 2000 .
} 
do Manuscrito de Genebra onde o corpo político é comparado a um composto químico, cf. ROUSSEAU, 1964, p. 284). De modo geral, recomendações de dieta e a defesa do aleitamento materno, que reconhecemos como temas fundamentais na doutrina pedagógica de Rousseau, são também temas recorrentes em diversos escritos médicos da época: Van Helmont, para citarmos apenas um exemplo de autoridade no assunto, era contrário ao uso do leite como alimento do bebê.

Os pontos comuns entre Rousseau e os médicos são vários, mas não se trata aqui de uma comparação de doutrinas almejando com isso uma pesquisa especializada de história das ideias científicas. Interessame nessas aproximações, com foco no Emílio, observar que a fabricação do conceito de criança nos coloca diante de duas constatações na atitude de Rousseau: (1) a novidade da preocupação com as doenças das crianças e os cuidados que a medicina propunha para a sobrevida delas, e (2) o reconhecimento de que o tratamento de uma criança doente é diferente do tratamento de um adulto doente. Nesses termos, podemos compreender de maneira objetiva as condições do debate científico nos anos que antecedem a gênese do Emílio e que, segundo minha interpretação, teriam conduzido Rousseau a conceber a ideia de "criança enquanto criança". Por isso, não acho absurdo afirmar que Rousseau participa do debate sobre a fisiologia de seu tempo, embora o faça indiretamente e à sua maneira; ora, se pudermos levar a sério essa tese, poderíamos operar uma revisão da bibliografia especializada no Emílio, uma vez que a relação entre a doutrina pedagógica de Rousseau e os debates na área da medicina tornariam questionáveis todas as interpretações da obra que tenham sido feitas à margem da história das ciências. Em suma, o que gostaria de afirmar aqui é que, se Rousseau consegue inventar a criança ao distinguir a ordem infantil da ordem da vida humana no registro do discurso filosófico, tal invenção tem raízes bastante empíricas, na medida em que diz respeito às transformações dos modelos explicativos do corpo 
humano encontrados nos textos de medicina da época. Cabe lembrar ainda que, de minha parte, não tenho a pretensão de apresentar uma interpretação nova do Emílio com esse viés de leitura: o que faço consiste apenas em mostrar um aspecto complementar às leituras consagradas dos estudos rousseauístas e das pesquisas em história da educação sobre Rousseau.

\section{Referências}

ANDRY DE BOIS-REGARD, Nicolas. L'Orthopédie, ou L'Art de prévenir et de corriger dans les enfants les difformités du corps. Paris, 1741. $2 \mathrm{v}$.

ARIÈS, Philippe. L'Enfant et la vie familiale sous l'Ancien Régime. Paris: Plon, 1960; trad. bras.: A história social da criança e da familia. $2^{\mathrm{a}}$ ed. Rio de Janeiro: LTC, 1981.

BADINTER, Elisabeth. L'Amour en plus: histoire de l'amour maternel (XVII $-X X^{e}$ siècle). Paris: Flammarion, 1980; trad. bras.: Um amor conquistado: o mito do amor materno. Rio de Janeiro: Nova Fronteira, 1986.

BENSAUDE-VINCENT, Bernadette; BERNARDI, Bruno (Org.). Rousseau et les sciences. Paris: L'Harmattan, 2003.

BLAYO, Yves. "La mortalité en France de 1740 à 1829”. Population Institut National d'Études Démographiques, v. 30, n. 1, 1975. https://doi.org/10.2307/1530647

BOERHAAVE, Hermann. Institutiones rei medicae in usus annuae exercitationis domestica. Leyde, 1708; versão em língua francesa: Institutions de médecine. Traduites par M. de La Mettrie. Deuxième édition. Paris, $1742.8 \mathrm{v}$.

BOERHAAVE, Hermann; VAN SWIETEN, Gerard. Traité des maladies des enfants. Avignon \& Paris, 1759.

BOERHAAVE, Hermann. Boerhaave's Orations. Leiden: E. J. Brill, 1983. 
BROUZET, Pierre. Essai sur l'éducation médicinale des enfans et sur leurs maladies. Paris, 1754. $2 \mathrm{v}$.

BOTO, Carlota. A liturgia escolar na Idade Moderna. Campinas: Papirus, 2017.

CANGUILHEM, G. La constitution de la physiologie comme science. In: CANGUILHEM, G. Études d'histoire et de philosophie des sciences. Paris: J. Vrin, 1975.

CERIZARA, Ana Beatriz. Rousseau: a educação na infância. São Paulo: Scipione, 1990.

CLAPARÈDE, Edouard. J.-J. Rousseau et la conception fonctionnelle de l'enfance. Revue de Métaphysique et de Morale, Paris, année XX, t. 3, 1912.

CLAPARÈDE, Edouard. Psychologie de l'enfant et pédagogie expérimentale. 6. ed. Genebra: Kundig; Paris: Fischbacher, 1916.

CLAPARÈDE, Edouard. L'Éducation fonctionnelle. Paris: Delachaux \& Niestlé, 1931; trad. bras.: A educação funcional. 5. ed. São Paulo: Companhia Editora Nacional, 1958.

CRIGNON, Claire et al. (Ed.). Medical Empiricism and Philosophy of Human Nature in the $17^{\text {th }}$ and $18^{\text {th }}$ Century. Leiden: Brill, 2013. https://doi.org/10.1163/9789004268135 PMid:25707095

DESESSARTZ, Jean-Charles. Traité de l'éducation corporelle des enfans en bas âge, ou Réfléxions pratiques sur les moyens de procurer une meilleure constitution aux Citoyens. Paris, 1760.

DUCHESNEAU, François. L'Empirisme de Locke. La Haye: Martins Nijhoff, 1973.

DUCHESNEAU, François. La Physiologie des Lumières: empirisme, modèles et théories. The Hague: Martinus Nijhoff, 1982.

ELIAS, Norbert. Über den Prozeß der Zivilisation. Basel: Verlag Haus zum Falken, 1939; trad. bras.: O processo civilizador, v. I: Uma história dos costumes. 2. ed. Rio de Janeiro: Jorge Zahar, 1994.

ERNOUT, Alfred; MEILLET, Alfred (Ed.). Dictionnaire étymologique de la langue latine: histoire des mots. Paris: Klincksieck, 2001. 
FASS, Paula (Dir.). Encyclopedia of Children and Childhood in History and Society. New York: Macmillan; Gale, 2004. https://doi.org/10.4324/9780203075715

FASS, Paula S. (Ed.). The Routledge History of Childhood in the Western World. New York: Routledge, 2013. https://doi.org/10.4324/9780203075715

FOUCAULT, Michel. Surveiller et punir: naissance de la prison. Paris: Gallimard, 1975.

FOUCAULT, Michel. Histoire de la sexualité, I: La Volonté de savoir. Paris: Gallimard, 1984; trad. bras.: História da sexualidade, I: A vontade de saber. 13. ed. Rio de Janeiro: Graal, 1999.

GAY, Peter. The Enlightenment: An Interpretation, v. II: The Science of Freedom. New York: Norton, 1977.

GELIS, Jacques. A individualização da criança. In: CHARTIER, Roger (Org.). História da vida privada, v. 3: da Renascença ao Século das Luzes. São Paulo: Companhia das Letras, 2009.

GRMEK, M. (Ed.). Histoire de la pensée médicale en Occident, v. 2: de la Renaissance aux Lumières. Paris: Seuil, 1997. https://doi.org/10.1016/S1246-7391(97)80275-8

HEYWOOD, Colin. A History of Childhood: Children and Childhood in the West from Medieval to Modern Times. Cambridge: Polity Press, 2001.

HULAK, Florence. En avons-nous fini avec l'histoire des mentalités ?, Philonsorbonne, Paris, n. 2007-2008. https://doi.org/10.4000/philonsorbonne.173

JIMACK, Peter D. La Genèse et la rédaction de l'Émile de J.-J. Rousseau: étude sur l'histoire de l'ouvrage jusqu'à sa parution. Genève: Institut et Musée Voltaire, 1960.

JIMACK, Peter D. Rousseau: Emile. London: Grant \& Cutler, 1983 (Critical Guides do French Texts, 28).

JOUANNA, Jacques. Hippocrate. Paris: Fayard, 1992. 
KAWAUCHE, Thomaz. Emílio e a medicina antiga. Educativa (PUCGO), Goiânia, v. $20, \quad$ n. $\quad 1, \quad 2017$. https://doi.org/10.18224/educ.v20i1.5870

KING, Lester S. The Philosophy of Medicine: The Early Eighteenth Century. Cambridge: Harvard University Press, 1978. https://doi.org/10.4159/harvard.9780674182165

KUHN, Thomas. A estrutura das revoluções científicas. São Paulo: Perspectiva, 2007.

LACAZE, Louis de. L'Idée de l'homme physique et moral, pour servir d'introduction à un traité de médecine. Paris, 1755.

LA MENTHEOUR, Rudy de. La Manufacture de maladies: la dissidence hygiénique de Jean-Jacques Rousseau. Paris: Classiques Garnier, 2011.

LA METTRIE, Julien Offroy de. L'Homme-machine. Ed. Paul-Laurant Assoun. Paris: Denoël; Gonthier, 1981.

LE CAMUS, Antoine. Médecine de l'esprit. Paris, 1753.

LINDEBOOM, G.A. Herman Boerhaave: The Man and his Work. London: Methuen, 1968.

MATTHEWS-GRIECO, S. F. Corps et sexualité dans l'Europe d'Ancien Régime. In: CORBIN, A. et al. (Ed.). Histoire du corps, v. 1: De la Renaissance aux Lumières. Paris: Seuil, 2005.

NEWTON, Isaac. Mathematical Principles of Natural Philosophy and his System of the World. Volume Two: The System of the World. Los Angeles: University of California Press, 1934.

PIMENTA, Pedro Paulo; SOUZA, Maria das Graças de (Dir.). Enciclopédia, ou Dicionário razoado das ciências, das artes e dos oficios, de Diderot \& D’Alembert. São Paulo: Edunesp, 2015 (volumes 1 a 5); 2017 (volume 6).

REBOLLO, Regina Andrés. O legado hipocrático e sua fortuna no período greco-romano: de Cós a Galeno. Scientiae Studia, São Paulo, v. 4, n. 1, 2006. 
RENAUT, Alain. La Libération des enfants: contribution philosophique à une histoire de l'enfance. Paris: Hachette, 2003.

REY, Roselyne. Naissance et développement du vitalisme en France de la deuxième moitié du $18^{e}$ siècle à la fin du Premier Empire. Oxford: Voltaire Foundation, 2000.

ROGER, Jacques. Les Sciences de la vie dans la pensée française du XVIII ${ }^{e}$ siècle. Paris: Armand Colin, 1963; trad. ingl.: The Life Sciences in Eighteenth-Century French Thought. Stanford University Press, 1997.

ROUSSEAU, Jean-Jacques. Euvres complètes. Éd. Bernard Gagnebin \& Marcel Raymond. Paris: Gallimard, 1964 (Tomo III); 1969 (Tomo V). ROUSSEAU, Jean-Jacques. Emílio, ou Da educação. Trad. Roberto Leal Ferreira. 2. ed. São Paulo: Martins Fontes, 1999.

SALOMON-BAYET, Claire. L'Institution de la science et l'expérience du vivant : méthode et expérience à l'Académie royale des sciences (1666-1793). Paris: Flammarion, 1978.

SEARS, Elizabeth. The Ages of Man: Medieval Interpretations of the Life Cycle. New Jersey: Princeton University Press, 1986.

SHAHAR, Shulamith. Childhood in the Middle Ages. New York: Routledge, 1990.

SNYDERS, Georges. La pédagogie en France aux XVII ${ }^{\mathrm{e}}$ et $\mathrm{XVIII}^{\mathrm{e}}$ siècles. In: DEBESSE, Maurice; MIALARET, Gaston (Dir.). Traité des sciences pédagogiques, 2: Histoire de la Pédagogie. Paris: Presses Universitaires de France, 1971.

TEMKIN, Owsei. Galenism: Rise and Decline of a Medical Philosophy. London: Cornell University Press, 1973.

TISSOT, Samuel Auguste. L'Onanisme, dissertation sur les maladies produites par la masturbation [1760]. $3^{\mathrm{e}}$ éd. Lausanne, 1764.

Data de registro: $30 / 11 / 2018$

Data de aceite: 24/04/2019 